\title{
Region-Specific Myelin Pathology in Mice Lacking the Golli Products of the Myelin Basic Protein Gene
}

\author{
Erin C. Jacobs, ${ }^{1}$ Thomas M. Pribyl, ${ }^{1}$ Kathy Kampf, ${ }^{1}$ Celia Campagnoni, ${ }^{1}$ Christopher S. Colwell, ${ }^{1}$ Samuel D. Reyes, ${ }^{1}$ \\ Melanie Martin, ${ }^{2}$ Vance Handley, ${ }^{1}$ Timothy D. Hiltner, ${ }^{2}$ Carol Readhead, ${ }^{2}$ Russell E. Jacobs, ${ }^{2}$ Albee Messing, ${ }^{3}$ \\ Robin S. Fisher, ${ }^{1}$ and Anthony T. Campagnoni ${ }^{1}$ \\ ${ }^{1}$ Neuropsychiatric Institute, University of California Los Angeles School of Medicine, Los Angeles, California 90024, ${ }^{2}$ Biological Imaging Center, Beckman \\ Institute, California Institute of Technology, Pasadena, California 91125, and ${ }^{3}$ Waisman Center and Department of Pathobiological Sciences, University of \\ Wisconsin-Madison, Madison, Wisconsin 53705
}

The myelin basic protein (MBP) gene encodes two families of proteins, the classic MBP constituents of myelin and the golli-MBPs, the function of which is less well understood. In this study, targeted ablation of the golli-MBPs, but not the classic MBPs, resulted in a distinct phenotype unlike that of knock-outs (KOs) of the classic MBPs or other myelin proteins. Although the golli KO animals did not display an overt dysmyelinating phenotype, they did exhibit delayed and/or hypomyelination in selected areas of the brain, such as the visual cortex and the optic nerve, as determined by Northern and Western blots and immunohistochemical analysis with myelin protein markers. Hypomyelination in some areas, such as the visual cortex, persisted into adulthood. Ultrastructural analysis of the KOs confirmed both the delay and hypomyelination and revealed abnormalities in myelin structure and in some oligodendrocytes. Abnormal visual-evoked potentials indicated that the hypomyelination in the visual cortex had functional consequences in the golli KO brain. Evidence that the abnormal myelination in these animals was a consequence of intrinsic problems with the oligodendrocyte was indicated by an impaired ability of oligodendrocytes to form myelin sheets in culture and by the presence of abnormal $\mathrm{Ca}^{2+}$ transients in purified cortical oligodendrocytes studied in vitro. The $\mathrm{Ca}^{2+}$ results reported in this study complement previous results implicating golli proteins in modulating intracellular signaling in T-cells. Together, all these findings suggest a role for golli proteins in oligodendrocyte differentiation, migration, and/or myelin elaboration in the brain.

Key words: oligodendrocytes; calcium imaging; dysmyelination; visual cortex; optic nerve; ablation

\section{Introduction}

The golli proteins are one of two families of products expressed by the myelin basic protein (MBP) gene (see Fig. 1). Unlike the classic MBPs, they do not appear to be components of the myelin sheath but are localized primarily within the cell bodies and primary processes of oligodendrocytes (OLs) (for review, see Campagnoni and Skoff, 2001). Transcription of the golli mRNAs begins at the most upstream promoter of the $m b p$ gene, and alternative splicing yields golli transcripts containing exons 1-3 plus varying exons further downstream, including exons that encode the classic MBPs. The major golli-MBPs (i.e., BG21 and J37) are structurally related to the classic MBPs in their C-terminal halves, because splicing of golli transcripts into the MBP-

\footnotetext{
Received Jan. 20, 2005; revised June 7, 2005; accepted June 9, 2005.

This work was supported by National Institutes of Health Grant NS23022 and National Multiple Sclerosis Society Grant RG2693 to A.T.C. We thank Birgitta Sjostrand and the University of California Los Angeles Brain Research Institute Electron Microscopic Core for specimen preparation and use of microscopic facilities.

Correspondence should be addressed to Dr. Anthony T. Campagnoni, Neuropsychiatric Institute, Room 47-448, University of California Los Angeles Medical School, 760 Westwood Plaza, Los Angeles, CA 90024-17519. E-mail: acampagnoni@mednet.ucla.edu.

T. M. Pribyl's present address: Beckman Coulter, Inc., 7330 Carroll Road, San Diego, CA 92121.

M. Martin's present address: Department of Physics, University of Winnipeg, Winnipeg, Manitoba, Canada, R3B 2E9.

DOI:10.1523/JNEUROSCI.0288-05.2005

Copyright $\odot 2005$ Society for Neuroscience $\quad$ 0270-6474/05/257004-10\$15.00/0
}

encoding exons occurs in frame. Thus, the two families of protein share MBP primary sequence and, consequently, MBP antigenic and binding determinants (see Fig. 1A) (Campagnoni et al., 1993; Kaur et al., 2003).

The golli-MBPs are more ubiquitously expressed throughout the nervous system and the immune system (Campagnoni et al., 1993; Pribyl et al., 1993; Landry et al., 1998) than are the classic MBPs, which are primarily products of myelin forming OLs. This, and their noninclusion in the myelin sheath, suggests that they have some other biological function than the classic MBPs. Although the primary biological role of the classic MBPs appears to be that of myelin structural components, the biological function of the golli proteins is only beginning to be understood (Campagnoni and Skoff, 2001). We found that golli proteins can modulate signaling in $\mathrm{T}$-cells through negative regulation of the PKC pathway (Feng et al., 2004). They also seem to be associated with process extension in neurons and OLs. They have been found to be expressed during embryonic development in neuronal populations during process extension and migration (Landry et al., 1998). Overexpression of golli induces a striking morphological effect on enhanced process and sheet elaboration in OL cell lines (Reyes and Campagnoni, 2002).

We have generated a golli knock-out $(\mathrm{KO})$ mouse in which we have selectively ablated the golli products of the $m b p$ gene, with- 
out ablating the expression of the classic MBPs. These golli KO mice have a complex phenotype reflecting the loss of golli expression in the two major systems in which they are expressed (i.e., the immune and nervous systems) and the cell types in which they are expressed within each system. Ablation of golli expression causes abnormalities in the immune system and its response to experimental autoimmune encephalomyelitis (Voskuhl et al., 2003). We have reported, in preliminary form, that the $\mathrm{KO}$ animals exhibit behavioral abnormalities (Olmstead et al., 2000) reflective of neuronal abnormalities, and we report here effects of the ablation of the golli products on OLs and myelination in selected regions of the brain. The data in this work indicate a role for golli proteins in myelin formation and maintenance, although its action appears to be more evident in some regions of the brain than others.

\section{Materials and Methods}

\section{Generation of the golli KO mice}

To create the construct for homologous recombination, $7.5 \mathrm{~kb}$ exon 2 -containing fragment of $129 \mathrm{SvEv}$ genomic DNA was cloned into the EcoRI-HindIII sites of pSport. Exon 2 (ablated by limited Exo III exonuclease digestion from a StuI site within the clone) was replaced by a neomycin (neo) poly(A) gene in the reverse orientation. As shown in Figure 1, the final clone contained $\sim 3.3 \mathrm{~kb}$ of genomic DNA upstream of the neo insertion and $1.2 \mathrm{~kb}$ downstream. The herpes simplex kinase 1 gene (a gift from Drs. E. Carpenter and M. Capecchi, University of Utah, Salt Lake City, UT) was added as a negative selection marker, and the completed construct was transfected into the AB-1 line of mouse embryonic stem (ES) cells (gift from Dr. A. Bradley, Baylor College of Medicine, Houston, TX). The resultant ES clones were injected into C57BL/6 blastocysts. A chimeric founder male was bred with C57BL/6J females. Through non-brother-sister crosses, a line was generated that is homozygous for the exon 2 ablation on a background that is $~ 50 \% 129 \mathrm{~S} 7 /$ SvEvBrd and 50\% C57BL6/J. A control line was established that was also $50 \% 129$ S7/SvEvBrd and 50\% C57BL6/J but was negative for the exon 2 ablation. The golli KO phenotype was observed before keeping the lines separate and then was studied over at least eight generations and remained stable.

\section{Genotyping}

High-molecular-weight genomic DNA was isolated from tail snippets by proteinase $\mathrm{K}$ digestion followed by phenol chloroform extraction. The insertion site of homologous recombination was checked by screening Southern blots with probes from the region of the genome on either side of the original pSport $7.5 \mathrm{~kb}$ fragment. As shown in the blot in Figure 1C, the $500 \mathrm{bp} \mathrm{BamHI-HindIII} \mathrm{black} \mathrm{(blk)} \mathrm{probe,} \mathrm{located} \mathrm{just} \mathrm{upstream} \mathrm{of}$ the original $\mathrm{KO}$ construct, reacts with a $7.0 \mathrm{~Kb} B a m \mathrm{HI}$ fragment in native genomic DNA and a $2.4 \mathrm{~kb}$ fragment in the ablated genome. Similarly, the blue probe (a $500 \mathrm{bp} E c o \mathrm{RV}-A p a \mathrm{I}$ fragment, located downstream of the $\mathrm{KO}$ construct) reacts with an $11.5 \mathrm{~kb}$ native DNA band and a $9 \mathrm{~kb}$ ablated one (data not shown). Animals were regularly genotyped either by Southern blot as above or by PCR with primers located at either end of golli exon 2: 5PM2, TGTTGGCAACTTTGGATGTGT and P3P, TCAGCCAAGCCTTACCTTACT, which gave a $214 \mathrm{bp}$ fragment in WT mice; and at either end of the neo insertion: neo 780, GCTTGGGTGGAGAGGCTATTC and neo 1520, TCCCCTCAGAAGAACTCGTCA, which yielded a $713 \mathrm{bp}$ fragment characteristic of KO mice. The PCR conditions for $1 \mu \mathrm{g}$ of DNA in $3 \mu \mathrm{M} \mathrm{Mg}^{2+}$ were $4 \mathrm{~min}$ at $94^{\circ} \mathrm{C}$, then 41 cycles for $1 \mathrm{~min}$ at $94^{\circ} \mathrm{C}, 45 \mathrm{~s}$ at $58^{\circ} \mathrm{C}$ and $1 \mathrm{~min}$ at $72^{\circ} \mathrm{C}$, followed by a 7 min extension at $72^{\circ} \mathrm{C}$.

\section{Analysis of the golli KO transgenic mice}

Analysis of mRNA expression. At each developmental time point, RNA was isolated from 12-18 mouse brains using the triazol method of Invitrogen (Carlsbad, CA). Each time point on the subsequent Northern analysis represents $20 \mu \mathrm{g}$ of total RNA probed first with a $535 \mathrm{bp}$ cDNA for the coding sequence of mouse $14 \mathrm{kDa} \mathrm{MBP}$ (pP535) and then stripped and probed with a mixture of a mouse cDNA for the coding sequence of proteolipid protein (PLP; BAS1013) and cyclophilin (kind gift from Dr. G. Sutcliffe, The Scripps Research Institute, La Jolla, CA). At each probing, the blot was analyzed on a PhosphorImager (Amersham Biosciences, Piscataway, NJ). Loading errors were corrected by normalizing the values for MBP or PLP time points to those for cyclophilin (P1B15).

Western blots. Protein was precipitated from the organic phase of the triazol RNA extraction with isopropanol according to manufacturer's instructions. The blot in Figure $2 B$ represents $5 \mu \mathrm{g}$ of brain protein in each lane probed with a rabbit polyclonal antibody raised against amino acids $1-115$ of bovine MBP. The blots in Figure $1 D$ represent $100 \mu \mathrm{g}$ of brain, spleen, or thymus proteins probed with an affinity-purified rabbit polyclonal antibody raised against amino acids $1-133$ of the golli proteins (the golli-specific peptide).

Tissue preparation. In this study, 32 transgenic animals and their wildtype (WT) littermates from postnatal day 12 (P12) $(n=4 \mathrm{WT}, 4 \mathrm{KO})$, P18 $(n=2,2), \mathrm{P} 28(n=4,3), \mathrm{P} 50(n=3,4)$, and P90 $(n=3,3)$ were prepared and analyzed for immunohistochemical and ultrastructural analyses. At each developmental time point, animals were anesthetized with halothane and given intracardiac perfusions with $4 \%$ buffered paraformaldehyde. After perfusion, tissues were removed and postfixed overnight at $4^{\circ} \mathrm{C}$. The fixed tissue was then cryoprotected in sucrose, frozen in OCT medium, and sectioned on a cryostat (3050S; Leica, Nussloch, Germany) at $20 \mu \mathrm{m}$. Sections were thaw-mounted onto Superfrost Plus microscope slides (Fisher Scientific, Pittsburgh, PA) and subsequently processed for immunohistochemistry. For ultrastructural analysis, animals were perfused with $2 \%$ glutaraldehyde $/ 2 \%$ paraformaldehyde in a sodium cacodylate buffer. Specific brain regions were then postfixed with $1 \% \mathrm{OsO}_{4}$, dehydrated, and embedded in Epon. Ultra-thin sections were stained with uranyl acetate and lead citrate and examined with a Jeol (Tokyo, Japan) JEM-100CX electron microscope. Qualitative assessment of the extent of myelination was made in comparable sections randomized within both golli KO and WT tissue (prechiasmatic optic nerve and medial 1 area of the visual cortex).

Immunohistochemistry. As described by Jacobs et al. (2003), frozen sections were pretreated with $3 \% \mathrm{H}_{2} \mathrm{O}_{2}, 10 \%$ methanol to quench endogenous peroxidase activity. Sections were then blocked for $1 \mathrm{~h}$ in $0.1 \%$ Triton X-100, $0.1 \%$ casein PBS and incubated overnight with either a polyclonal antibody against $\mathrm{MBP}^{1-115}$ peptide (1:8000) or a rat monoclonal antibody against PLP (AA3; 1:200; a gift from Dr. K. Ikenaka, Okazaki National Research Institutes, Okazaki, Japan) diluted in $0.1 \%$ Triton X-100, 0.1\% casein in PBS. The localization of the antibodies was visualized by the immunoperoxidase method (ABC kit; Vector Laboratories, Burlingame, CA) with 3, 3' -diaminobenzidine (Roche, Indianapolis, IN) as the chromagen per the manufacturer's instructions. Images were obtained using a Leica DM RXA microscope with a Spot CCD camera (Diagnostic Instruments, Sterling Heights, MI) and assembled into figures using Adobe Photoshop 6.0 software (Adobe Systems, San Jose, CA). Using the line-intercept method, density measurements of labeled myelin profiles (number of labeled fiber intercepts per $10 \mu \mathrm{m}$ ) were determined within the outer plexiform zone (layer 1), the middle zone (layers 2/3), and deeper zone (layer 4 to the corpus callosum) within the visual cortex of coronal sections from three KO and three WT P50 brains. Comparable regions of the medial 1 area of the visual cortex were selected in all animals, and lines perpendicular to the tangent of the pial surface were used in all measurements. Statistical significance of differences of the mean was determined using a one-tailed Student's $t$ test.

Preparation of primary mixed glial cultures and immunocytochemistry. The method used for preparing primary mixed glial cultures was in accordance with that described by Amur-Umarjee (1990). Briefly, mechanically dissociated cerebral hemispheres from 0 - to 3-d-old mice were plated on polylysine-coated coverslips in DMEM/Ham's F12 media containing $6 \mathrm{~g} / \mathrm{L}$ glucose and 10\% fetal bovine serum (FBS). After growing for $21 \mathrm{~d}$ in vitro, the cells were rinsed briefly in PBS and fixed in $4 \%$ buffered paraformaldehyde for $30 \mathrm{~min}$ at room temperature. After rinsing in PBS, the cells were permeabilized with $0.1 \%$ Triton X-100 in PBS for $10 \mathrm{~min}$ at room temperature and then processed for immunocytochemistry following the protocol as outlined by Reyes et al. (2002). Essentially, fixed cells were incubated in a blocking solution (5\% goat se- 
rum in PBS) followed by an overnight incubation at $4^{\circ} \mathrm{C}$ with a polyclonal antibody for MBP (1:700). Staining with anti-galactocerebroside antibody 01 (1:20) was performed on live cells without permeabilization for $1 \mathrm{~h}$ at room temperature before fixation. Coverslips for both antibodies were then incubated with FITC-conjugated secondary antibodies (1:200; Jackson ImmunoResearch Laboratories, West Grove, PA), mounted onto slides with Aquamount (Lerner Laboratories, Pittsburgh, PA), and fluorescent images were obtained using a Leica upright DMRXA microscope. Cell surface measurements were made using Spot 3.5.2 software (Diagnostic Instruments) on randomly selected, individual WT $(n=47)$ and KO $(n=57)$ cells pooled from five different preparations (six to eight animals per preparation for each genotype) immunostained for either MBP or 01. Statistical significance of differences was determined using the Mann-Whitney rank-sum test.

Calcium imaging: preparation of oligodendrocytes. Enriched oligodendrocytes were prepared as described by Amur-Umarjee et al. (1993). First, cerebral hemispheres from 0 - to 1 -d-old mice were mechanically dissociated and were plated on polylysine-coated flasks in DMEM/Ham's F12 media containing $6 \mathrm{~g} / \mathrm{L}$ glucose and $10 \%$ FBS. At 14 d, oligodendrocytes were purified from the mixed glial culture by the differential shaking and adhesion procedure by Suzumura et al. (1984) and allowed to grow for $2 \mathrm{~d}$ on polylysine-coated coverslips. At this stage, they had ample processes but were just beginning to express the OL markers 04 and 01.

Calcium imaging. Methods were similar to those described previously (Colwell, 2000; Michel et al., 2002; Paz Soldan et al., 2003). Briefly, a cooled CCD camera (Microview model; $1317 \times 1035$ pixel format; Princeton Instruments, Monmouth Junction, NJ) was added to the Olympus (Melville, NY) fixed-stage microscope to measure fluorescence. To load the dye into cells, the coverslips were washed in serum and phenol red-free DMEM, and the cells were incubated for $45 \mathrm{~min}$ at $37^{\circ} \mathrm{C}$, $5 \% \mathrm{CO}_{2}$ in the same media containing a final concentration of $4 \mu \mathrm{M}$ fura-PE3 (AM) (Teflabs, Austin, TX) plus 0.08\% Pluronic F-127 (Molecular Probes, Eugene, OR), then washed four times in DMEM and stored in DMEM for 0 - $4 \mathrm{~h}$ before being imaged (Paz Soldan et al., 2003). Resting calcium levels were made both in serum-free DMEM, which contains $1.8 \mathrm{mM} \mathrm{Ca}^{2+}$, and in serum-free HBSS containing $2 \mathrm{mM} \mathrm{Ca}^{2+}$ but no $\mathrm{Mg}^{2+}$. Other measurements were made in HBSS. Calcium influx and resting $\mathrm{Ca}^{2+}$ levels were measured on individual cells, and the results were pooled from three to five separate coverslips representing two to four separate oligodendrocyte preparations from 5-20 animals per preparation for each condition. Statistical significance of differences was determined using the Mann-Whitney rank-sum test.

The fluorescence of fura- 2 was excited alternatively at wavelengths of 357 and $380 \mathrm{~nm}$ by means of a high-speed wavelength-switching device (Lambda DG-4; Sutter Instruments, Novato, CA). Image analysis software (MetaFlour; Universal Imaging Corporation, West Chester, PA) allowed the selection of several "regions of interest" within the field from which measurements are taken. To minimize bleaching, the intensity of excitation light and sampling frequency was kept as low as possible. In these experiments, measurements were normally made once every $2 \mathrm{~s}$.

Calibration of $\mathrm{Ca}^{2+}$ signals. Free $\left[\mathrm{Ca}^{2+}\right]$ was estimated from the ratio $(R)$ of fluorescence at 357 and $380 \mathrm{~nm}$, using the following equation: $\left[\mathrm{Ca}^{2+}\right]=K_{\mathrm{d}} \times$ slope factor $\times\left(R-R_{\min }\right) /\left(R_{\max }-R\right)($ Grynkiewicz et al., 1985). The $K_{\mathrm{d}}$ was assumed to be $135 \mathrm{nM}$, whereas values for $R_{\min }$ and $R_{\max }$ were all determined via calibration methods. An in vitro method was used to make estimate values. With this method, rectangular glass capillaries were filled with a high-Ca ${ }^{2+}$ (fura-2 plus $10 \mathrm{mM} \mathrm{Ca}^{2+}$ ), a low- $\mathrm{Ca}^{2+}$ (fura-2 plus $10 \mathrm{~mm}$ EGTA), and a control solution without fura-2. The fluorescence (F) at $380 \mathrm{~nm}$ excitation of the low- $\mathrm{Ca}^{2+}$ solution was imaged, and the exposure of the camera adjusted to maximize the signal. These camera settings were then fixed, and measurements were made with 380 and $357 \mathrm{~nm}$ excitation of the three solutions. $R_{\min }=$ $\mathrm{F} 357 \mathrm{~nm}$ in low $\mathrm{Ca}^{2+} / \mathrm{F} 380$ in low $\mathrm{Ca}^{2+} ; R_{\max }=\mathrm{F} 357$ in high $\mathrm{Ca}^{2+} / \mathrm{F} 380$ in high $\mathrm{Ca}^{2+} ; \mathrm{Sf}=\mathrm{F} 380$ in low $\mathrm{Ca}^{2+} / \mathrm{F} 380$ in high $\mathrm{Ca}^{2+}$.

Visual-evoked potential measurements. Vision-evoked potential (VEP) measurements were performed in a similar manner to previous experiments (Strain and Tedford, 1993, Martin et al., 2003). Mice were anesthetized using isoflurane and thermoregulated at a core body temperature of $37^{\circ} \mathrm{C}$. In each case, the head was positioned with a stereotaxic positioning device housed in a covered, custom-built Faraday cage to reduce electronic noise and leakage of light from nonstimulus sources. The mice were allowed to reach a steady state with the anesthetic and dark-adapted for 20 min before recording the VEPs. A flashing visual stimulus was generated with a home-built strobe light $(2 \mathrm{~Hz})$ positioned at a fixed distance $(20 \mathrm{~cm})$ directly in front of the mouse in a darkened room. Subcutaneous platinum needle recording electrodes were positioned at $\mathrm{Fpz}$ (midline, just distal to the intraorbital line), $\mathrm{Oz}$ (midline, nuchal crest), and a ground placed on the hindlimb of the mouse. A DAM 50 differential amplifier, (World Precision Instruments, New Haven, CT) with a high-pass filter at $1 \mathrm{~Hz}$ and a low-pass filter at $1 \mathrm{kHz}$ was used to amplify the VEP at a gain of 10,000. The voltage measurements were digitized and recorded with Labview (National Instruments, Austin, TX) for $250 \mathrm{~ms}$ after each strobe flash for subsequent averaging across stimulus trials (1000 trials per recording session). The strobe light and Labview recordings were triggered by the same external source. After filtering out spontaneous EEG shifts not associated with stimulus delivery, VEPs averaged by case were subsequently pooled and averaged by group for age and genotype to allow statistical comparisons of grouped data.

\section{Results}

\section{Selective ablation of the golli-MBPs in golli KO mice $\left(\right.$ golli $\left.^{-/}\right)$}

Exon 2 of the $m b p$ gene was deleted to generate the golli KO mice. This approach was used because this exon contains the translation initiation site for all golli transcripts, and its deletion would lead to the selective ablation of only the golli family of products of the $m b p$ gene but not the classic MBP family (Fig. $1 A$ ). The KO mice were generated as detailed in Materials and Methods and analyzed by Southern and Western blot analyses, as well as reverse transcription-PCR (RT-PCR), to assure deletion of the golli products. Figure $1 B$ illustrates the targeting construct used to generate the mutation in ES cells. An ES cell line was obtained with the expected genomic structure, and it was injected into C57BL/ 6 blastocysts to create chimeric founders. The targeted allele was transmitted to the offspring of the founders, which were subsequently interbred to obtain golli $^{+/+}$, golli ${ }^{+/-}$, and golli $^{-1-}$ mice, as detected by Southern blot analysis, an example of which is shown in Figure $1 C$. This figure illustrates a HindIII digest of genomic DNA probed with a genomic DNA segment that lies upstream of exon 2 (designated the blk probe). In WT mice, this probe reveals a characteristic band at $7 \mathrm{~kb}$, but in DNA containing the null allele, the band is $2.4 \mathrm{~kb}$. Shown in Figure $1 C$ are the patterns for WT, heterozygous, and homozygous mice. Western blot analysis (Fig. 1D) and RT-PCR (data not shown) confirmed the loss of golli expression in the homozygous KOs versus WT in both the brain and immune system.

\section{Delay in classic MBP expression in the golli KO mice}

Having established the selective ablation of golli in the brain, we examined the golli $\mathrm{KO}$ animals for phenotypic differences associated with cells that normally express golli proteins. We began by examining typical markers of the myelin proteins, known to be indicators of the structural and functional integrity of OLs. The levels of classic MBP and PLP/DM20 mRNAs in the developing brains of golli $\mathrm{KO}$ and WT mice were determined by Northern blot analysis and quantification by phosphorimage analysis. Figure $2 \mathrm{~A}$ shows the results of such an analysis. There was a short delay in the peak expression of classic MBP mRNAs in the whole brains of the KO mice. In the case of the PLP/DM20 mRNAs, although the developmental pattern was broader in the KO mice, there did not appear to be a similar delay in the expression of these mRNAs.

The delay in expression of classic MBP mRNAs was confirmed by Western blot analysis of the whole brains of KO and WT mice 
A.
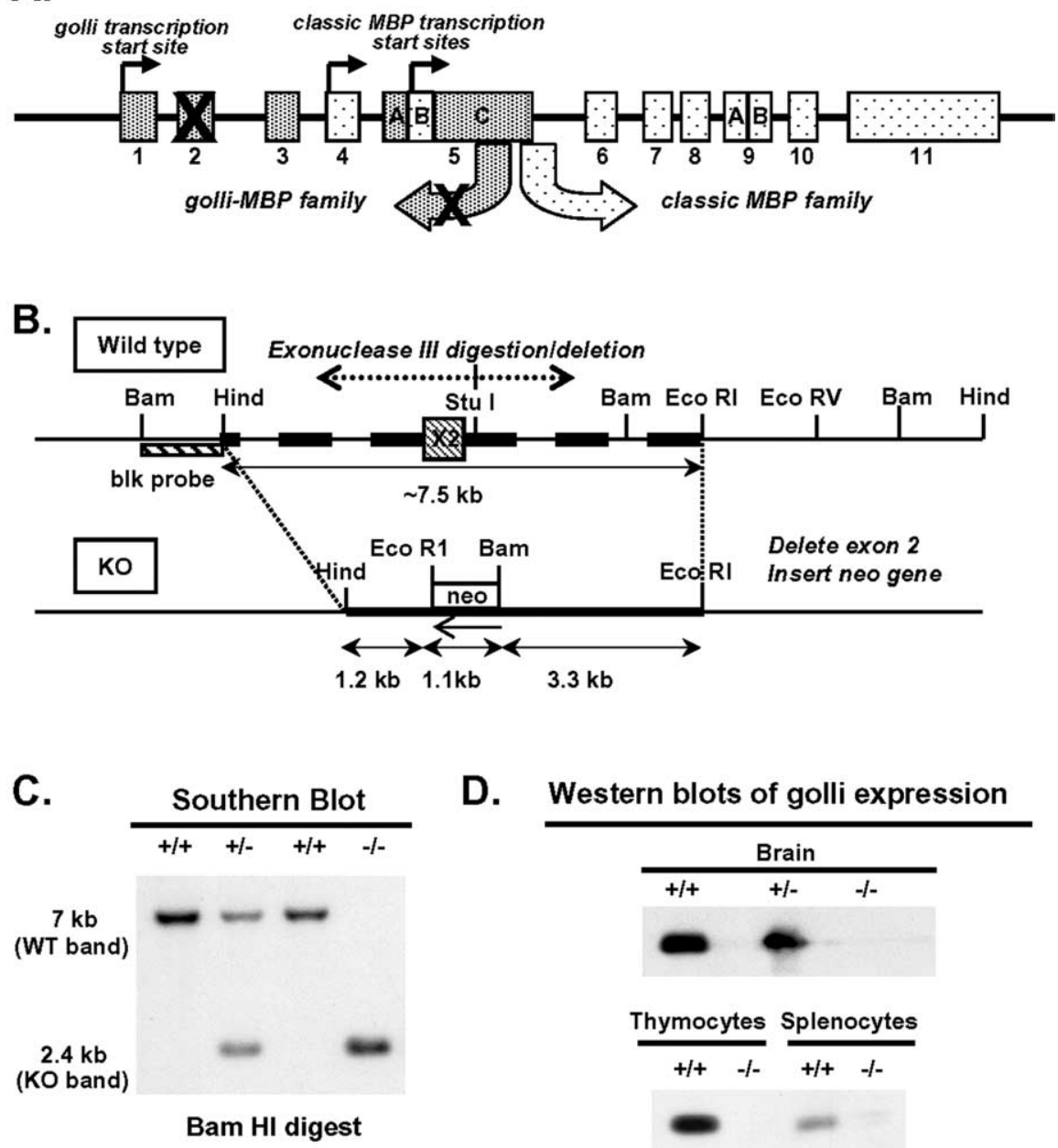

Figure 1. Golli KO mouse strategy. $\boldsymbol{A}$, Diagram of the MBP gene. $\boldsymbol{B}$, Golli KO mice were generated by replacing exon 2 of the $m b p$ gene with a neo resistance gene oriented in the opposite direction, thereby ablating expression of golli-MBPs but not the classic MBPs. C, Southern blot of genomic DNA digested with HindIII and hybridized to the blue probe. Note the loss of the exon 2 band $(11.5 \rightarrow 9 \mathrm{~kb})$ in the homozygous KO mice $(-/-)$, the presence of both bands in the hemizygous KO mice $(+/-)$, and the presence of the exon 2 band in the WT mice. $\boldsymbol{D}$, Western blots illustrating the loss of golli expression in the thymus, spleen, and brain in the homozygous $\mathrm{KO}$ mice.

(Fig. 2B). There was significantly less classic MBP at P12 in the golli $\mathrm{KO}$ versus WT, but at later ages, levels seemed comparable. The apparent discrepancy in the peaks of mRNA versus protein expression is probably because of the fact that the Western blots represent an accumulation of classic MBP, in which differences would be most evident during the early, logarithmic phase of developmental expression. In contrast, the mRNA analyses represent the steady-state levels of classic MBP mRNAs at any given age and do not represent accumulation, because the mRNAs are less stable than the proteins they encode.

Another measure of a delay in myelination can be obtained by examining primary cultures of OLs for their ability to elaborate myelin-like sheets, which are easily detected by immunocytochemical analyses with myelin markers. Such cultures can also reveal whether effects on myelination are intrinsic to the OL as opposed to external, environmental, or systemic influences. Figure 3 shows examples of KO and WT OLs grown in culture for $21 \mathrm{~d}$ and stained for MBP. Although the KO OLs elaborated membrane sheets (Fig. 3C,D), they were not as extensive as those elaborated by WT OLs (Fig. $3 A, B$ ). The observed morphological differences also were assessed by quantitative measurements of the median membrane surface areas of $\mathrm{KO}$ and WT OLs using two different OL markers. KO OLs had $\sim 36 \%$ of the control surface area when immunostained for MBP (889.21 vs $\left.317.08 \mu \mathrm{m}^{2} ; p<0.001\right)$ and $44 \%$ of the control when immunostained with 01 (480.47 vs $211.53{\mu \mathrm{m}^{2} ; p<}^{2}$ $0.001)$. Because we routinely generate our cultures using cerebral cortices of newborn mice, these results are consistent with a delay in or repression of myelination at least in the cortex of KO mice. The results also suggest the delay is intrinsic to the KO OLs.

\section{Ultrastructural analyses reveal delayed or impaired myelin sheaths in the KO mouse.}

The KO and WT nervous systems were surveyed for evidence of delayed or abnormal myelination by electron microscopy (Figs. 4, 5). Because the light microscopy studies revealed the most notable differences between the genotypes in occipital visual neocortex, we focused our anatomical studies on the neocortical and optic nerve components of the visual system. This also provided a comparison for distinguishing alterations of myelination in traditional "gray" and "white" matter structures.

Electron microscopy of the visual cortex revealed significantly fewer myelinated axons in the $\mathrm{KO}$ than in the corresponding regions of the WT between $\mathrm{P} 12$ and $\mathrm{P} 49$ (Fig. 4C,E, respectively). This difference tended to increase with age as myelinogenesis proceeded to stable adult levels in WT but not in the KO mice. Although the paucity of myelinated profiles was evident throughout the cortical laminas in $\mathrm{KO}$ mice, it was particularly prominent in layers I (Fig. $4 F$ ) and VI (Fig. $4 H$ ), normally sites of frequent myelin profiles in WT mice. Although the defects of myelination in layer VI could have impacted saltatory conduction along corticopetal, corticofugal, and/or intrinsic (commissural, associational, and local) axons of the neocortex, the defects in layer I would have arisen mainly from defective myelination of the intrinsic axonal connections.

The myelin profiles of $\mathrm{KO}$ mice were less frequent than those found in WT mice. When encountered, the myelin profiles of KO mice appeared to have multiple lamellas that tended to increase as development progressed. The KO profiles contained normal, albeit somewhat poorly compacted, arrangements of intraperiod and interperiod lines. Although not apparent at the magnifications in Figures 4 and 5, there was another structural difference noted in the WT and KO specimens. The normal appearance of myelin in the WT mice of a heavy major dense line and less dense minor line, typical of aldehyde-fixed and osmicated electron microscopy preparations, was altered in the $\mathrm{KO}$ mice in which the interperiod and intraperiod lines were of essentially equal staining intensity. The significance of this is not yet clear and requires additional investigation. 
A
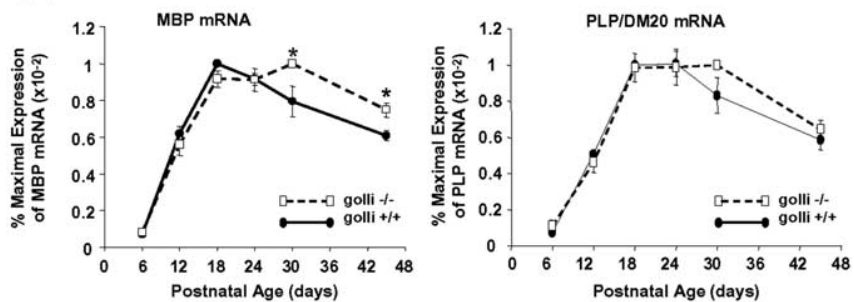

B

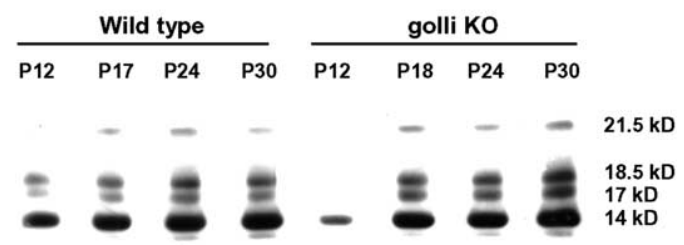

Figure 2. Developmental expression of MBP and PLP/DM20 genes in the golli KO brain. $\boldsymbol{A}_{t}$ Northern blot data from golli $\mathrm{KO}(-/-)$ and WT $(+/+)$ mice from P6 to P45. Peak expression of MBP mRNA levels was developmentally delayed in the KO mice relative to the WT controls. The asterisks indicate significant differences between WT and KO at that age. Delays in the expression of PLP/DM20 mRNAs in the K0 mice were not as apparent. Error bars are shown as SEM. $\boldsymbol{B}$, Western blot analysis of classic MBP isoforms in golli $\mathrm{KO}$ and WT brains from P12 to P30. The blots suggest a developmental delay in MBP expression in the KO mice relative to WT controls. Note the absence of the 18.5 and $17 \mathrm{kDa}$ MBP bands in the P12 K0.

Many of the cell bodies of neocortical OLs seen in the KO mice exhibited some degree of persistent vacuolization in the perikaryal cytoplasm (Fig. 4G). This sign may represent the presence of a continuing pathology among the myelinforming cells.

In contrast to the mixed and interactive cellular composition of neocortex, the main intrinsic cells of the optic nerve are myelinating OLs, which support the centripetal axons of retinal ganglion neurons. Thus, the optic nerve is often considered to be a model of a "pure" CNS myelinated tract. Here, the typical myelination of both small- and large-diameter axonal fibers was slightly delayed but essentially preserved from P12 to P49. Nonetheless, the optic nerve myelin of KO mice was structurally abnormal in that it was persistently less compacted than in WT mice. This defect was more notable in young mice and tended to be corrected to some extent as development progressed. Electron photomicrographs of myelinated axons in optic nerves from P19 golli KO and WT littermate control mice are shown in Figure 4, $B$ and $A$, respectively. At this age in the golli $\mathrm{KO}$ mice, the myelin sheaths were clearly less compact than in the controls (e.g., note the increased space between the axon and the mesaxon). At all ages examined (up to P49), the myelin profiles tended to be thinner, less elaborate, and less compacted (Fig. 5A-F). These signs of delayed or impaired myelination were evident at P12, even before eye opening (Fig. 5, compare $A, D$ ). At P12 in the WT animals, a mixture of myelin profiles, representing various stages of myelination, were observed (Fig. 5G). Although this inherent developmental variability was still apparent in the P12 KO mice (Fig. $5 H-J)$, we observed abnormal membrane elaboration and impaired myelination at a greater frequency in the $\mathrm{KO}$ samples than in the WTs. Furthermore, the impaired myelination in the KO mice was sometimes associated with axonal degeneration (Fig. 5I).
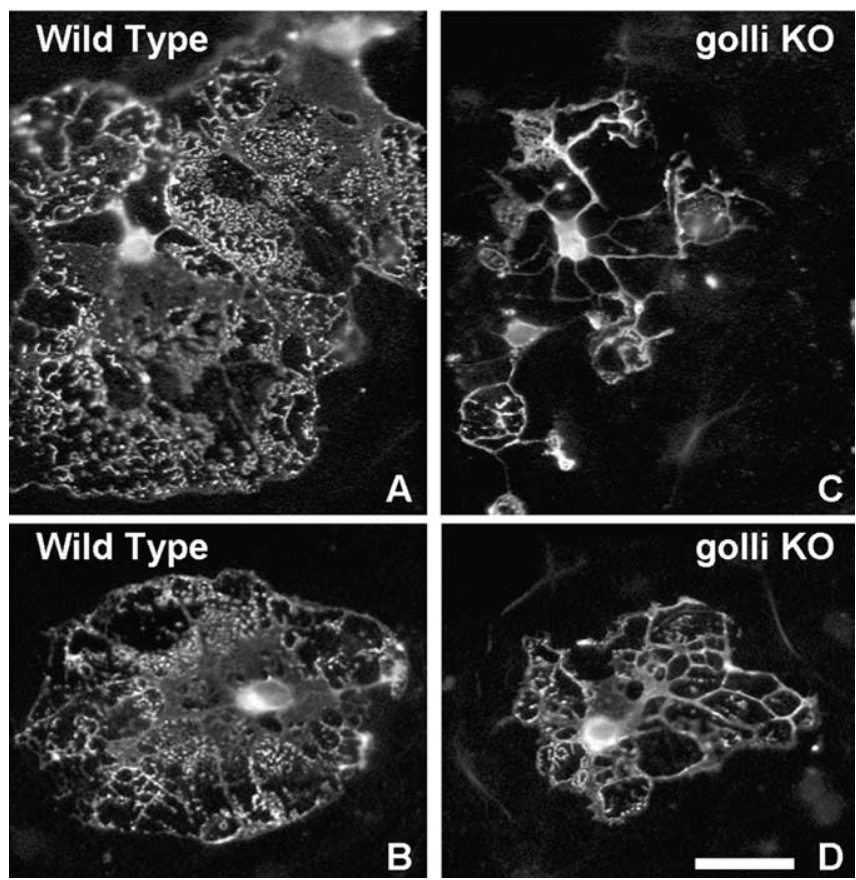

Figure 3. Wild-type $(\boldsymbol{A}, \boldsymbol{B})$ and golli $\mathrm{KO}(\boldsymbol{C}, \boldsymbol{D})$ OLs grown $21 \mathrm{~d}$ in culture and stained for MBP The truncated sheets elaborated by the KO OLs compared with WT suggest impaired myelin membrane formation. Scale bar: (in $\boldsymbol{D}) \boldsymbol{A}-\boldsymbol{D}, 30 \mu \mathrm{m}$.

Selective, region-specific hypomyelination in the golli KO mice results in functional abnormality

We examined the cerebral cortices of the golli KO mice by immunohistochemistry for classic MBPs and myelin PLP/DM20. Although overall levels of myelination, as assessed by MBP and PLP immunostaining, were similar in the $\mathrm{KO}$ and WT mice, certain specific areas were clearly hypomyelinated, in particular the visual cortex. Immunohistochemistry for MBP and PLP detected fewer labeled cells and fibers in the $\mathrm{KO}$ visual cortex (Fig. $6 B, D, F$ ) than in the WT littermates (Fig. $A, C, E$ ), confirming the reduction in myelinated profiles in this region, as shown in the electron micrographs in Figure 4. Together, the results indicate that this region of the cortex was hypomyelinated as early as P12, and this continued to at least P90. At both younger (Fig. 6A,B) and older (Fig. 6C-F) ages, immunohistochemical labeling was sparse in the visual cortex. At P50 (Fig. 7A-D), both the plexiform outer zones of layer 1 near the pial surface and the underlying cellular zones of the KO mice were significantly less labeled. Specifically, the density of labeled myelin profiles was reduced by $82 \%(p<0.05)$ in layer $1,83 \%$ in layers $2 / 3(p<0.05)$, and $68 \%$ in the deeper layers (layer 4 to the corpus callosum) (Fig. $7 E$ ). However, within a genotype, the density of PLP and MBP fibers was the same for any given layer (Fig. 7E). This reduction in labeled cells and fibers may be because of impaired OL migration into these regions during development that results in fewer myelinating OLs and/or to dysmyelination (Fig. 6A,B). Whatever the mechanism, hypomyelination in these regions persisted into adulthood. Labeled fiber density in other sensory cortices such as primary somatosensory and auditory cortices was reduced to a lesser extent than observed in the visual cortex (data not shown).

\section{Hypomyelination in the visual cortex has}

functional consequences

To determine whether the hypomyelination observed in the visual cortices of the golli KO mice had any functional relevance, 

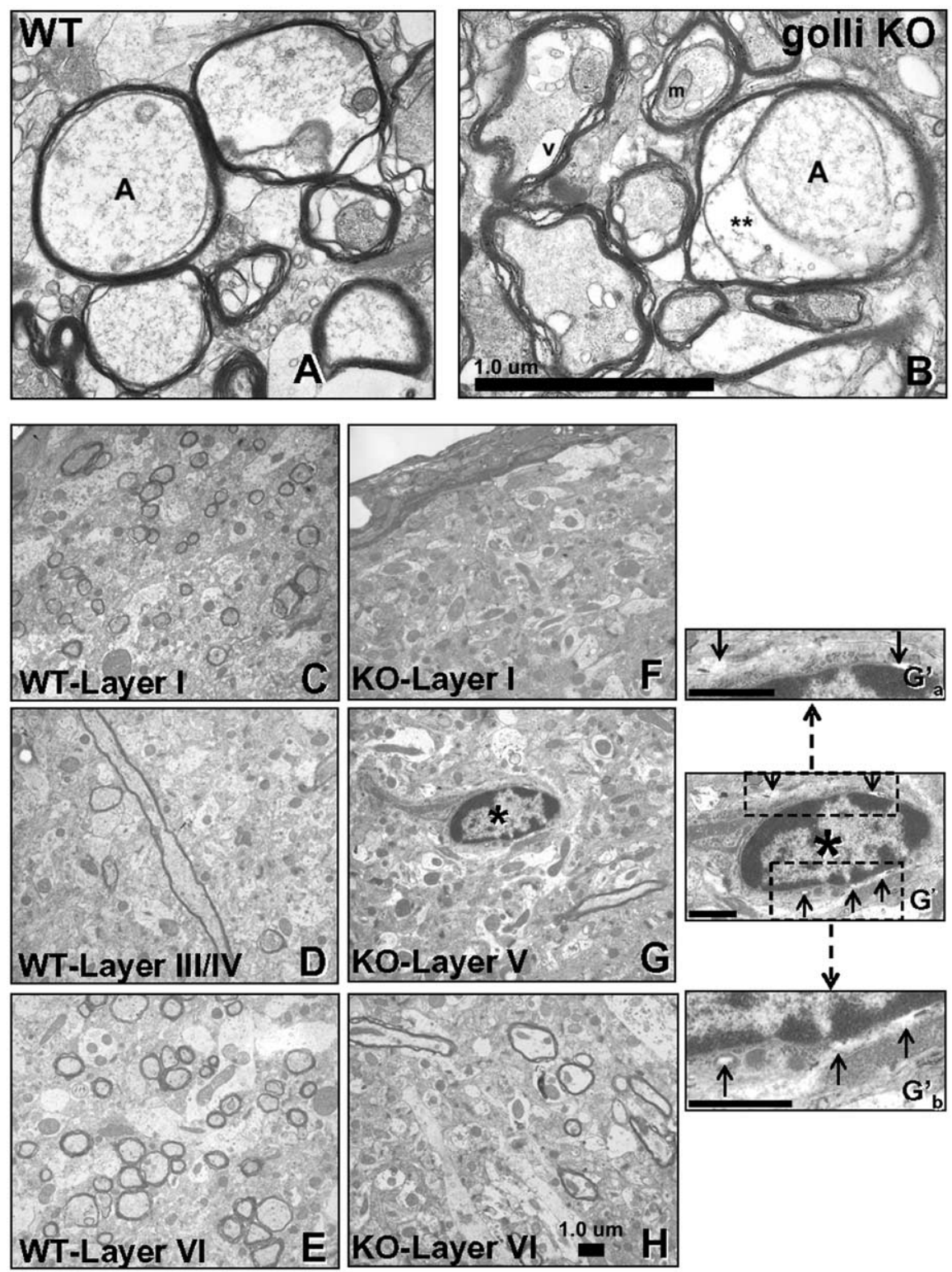

Figure 4. $\quad \boldsymbol{A}, \boldsymbol{B}$, Electron photomicrographs of myelinated axons in optic nerves from P19 golli KO $(\boldsymbol{B})$ and littermate WT control (A) mice. The myelin in the $\mathrm{KO}$ mouse typically was less compacted at this age. ${ }^{* *}$ represents the increased space within the mesaxon. A, axon; $m$, mitochondrion; $v$, vesicle. $\boldsymbol{C}-\boldsymbol{H}$, Electron photomicrographs of the visual cortex of P49 K0 and WT mice. More myelinated axons were present in the WT cortex, particularly in layers $(\boldsymbol{C})$ and VI $(\boldsymbol{E})$ than in the $K 0(\boldsymbol{F}, \boldsymbol{H}$, respectively). An example of an $\mathrm{OL}\left({ }^{*}\right)$, typical of the KO mice, is shown in $\mathbf{G}$. Some abnormal vacuolization was apparent in its perikaryal cytoplasm (arrows in $\boldsymbol{G}^{\prime}$ and at higher magnification in $\mathbf{G}^{\prime}{ }_{\boldsymbol{a}}$ and $\boldsymbol{G}^{\prime}{ }_{\boldsymbol{b}}$ ) and possibly represents pathogenic effects in some myelinating cells. Scale bars: (in $\boldsymbol{B}) \boldsymbol{A}, \boldsymbol{B}, 1.0 \mu \mathrm{m}$; (in $\boldsymbol{H}) \boldsymbol{C}-\boldsymbol{H}, 1.0 \mu \mathrm{m}$.

we conducted a VEP analysis on the KO mice versus littermate controls. The results indicated a physiological abnormality in the neocortex of golli KO mice. The VEP patterns were significantly different in the golli KO homozygotes versus WT controls. Figure 8 shows the averaged results of VEP analyses of four WT and three $\mathrm{KO}$ mice. Wave 1 results from signal transmission arising in the retina, through the thalamus, to the visual cortex, and waves 2 and 3 give the latencies of signal transmissions within the visual cortex and across hemispheres. The results indicate that cortical (but not subcortical) sources of VEP waves 2 and 3 are delayed, indicative of impaired salutatory conduction attributed to impaired myelination, in the golli $\mathrm{KO}$ mice (Fig. 8). These results suggest that waves derived from cortical connections [e.g., local (wave 2) and commissural-associational (wave 3) axonal collat- erals] are abnormal in golli $\mathrm{KO}$ mice and provide a physiological correlate of the hypomyelination observed in the histological studies of this region. Interestingly, the defects of myelin compaction evident in the optic nerves of the golli $\mathrm{KO}$ mice did not appear to impact the physiological function of the pathways contributing to the initiation of wave 1 of the VEP. Diminished frequency of myelinated axons arising from specific neuronal connections, not simple defects of the compaction process of myelinogenesis, seems to be the source of these functional abnormalities in golli $\mathrm{KO}$ mice.

\section{$\mathrm{Ca}^{2+}$ homeostasis is altered in purified oligodendrocytes isolated from golli KO mice}

Intracellular calcium is thought to be a critical regulator of growth and myelination (Soliven, 2001). To determine whether $\mathrm{Ca}^{2+}$ homeostatic mechanisms might be altered in OLs from gollideficient mice, primary cultures of purified $\mathrm{KO}$ and WT OLs were loaded with a membrane-permeable form of the $\mathrm{Ca}^{2+}$ indicator dye fura-2. Although resting $\mathrm{Ca}^{2+}$ levels did not differ between the two genotypes (WT,70 $\pm 1 \mathrm{nM}, n=396$ cells; $\mathrm{KO}, 66 \pm 1 \mathrm{nM}, n=412$ ), the magnitudes of the $\mathrm{Ca}^{2+}$ response to a variety of stimuli were significantly blunted in the KO OLs. For example, in WT OLs, bath application of a solution containing high potassium $\left(\mathrm{HiK}^{+} ; 20 \mathrm{~mm}, 120 \mathrm{~s}\right)$ caused an average $\mathrm{Ca}^{2+}$ increase of $47 \pm 4 \%(n=78)$. This response was widespread within the $\mathrm{OL}$ cultures, with $85 \%$ of cells examined showing a $\mathrm{Ca}^{2+}$ increase of $10 \%$ or greater. The average duration of the response (measured as the amount of time the signal was at least $50 \%$ of its peak value) was $217 \mathrm{~s}$, with $\mathrm{Ca}^{2+}$ levels in most of these cells returning to baseline levels within 360 s. The $\mathrm{HiK}^{+}$-induced $\mathrm{Ca}^{2+}$ transients were significantly reduced by removal of extracellular $\mathrm{Ca}^{2+}$ or by treatment with the $\mathrm{Ca}^{2+}$ channel blocker cadmium $\left(0 \mathrm{Ca}^{2+}\right.$ plus $\mathrm{HiK}^{+}, 8 \pm 1, n=49$; $\mathrm{Cd}^{2+}$ plus $\mathrm{HiK}^{+}, 9 \pm 1$, $n=33)$. In OL cultures from the golli $\mathrm{KO}$ mice, the $\mathrm{Ca}^{2+}$ transient induced by $\mathrm{HiK}^{+}$were significantly smaller $(20 \pm 2 ; n=77$; $p<0.001)$. In these cultures, only $56 \%$ of cells examined showing a $\mathrm{Ca}^{2+}$ increase of $10 \%$ or greater. If we excluded the nonresponding cells, there was still a significant difference between the group means (WT, $56 \pm 4 \%$ vs $\mathrm{KO}, 30 \pm 3 \%$ ).

In addition to $\mathrm{HiK}^{+}$, glutamate receptor agonists, including AMPA, are known to induce $\mathrm{Ca}^{2+}$ influxes in OLs (Itoh et al., 2002). In OLs from WT mice, application of AMPA $(25 \mu \mathrm{M})$ caused an average $\mathrm{Ca}^{2+}$ increase of $31 \pm 3 \%(n=70)$. The calcium transients induced by AMPA in the OL from golli $\mathrm{KO}$ mice were significantly smaller $(19 \pm 2 ; n=63 ; p<0.01)$

The magnitude of $\mathrm{Ca}^{2+}$ transients induced by PMA and caf- 

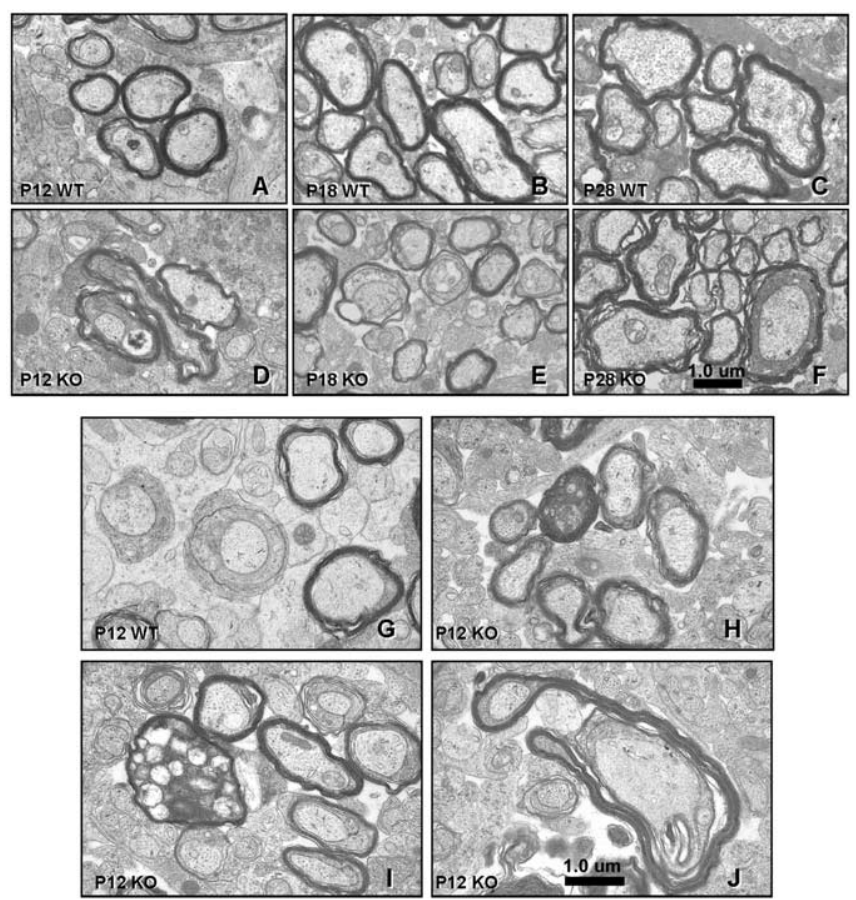

Figure 5. Electron photomicrographs of myelinated axons in optic nerves at P12, P18, and P28. In the developmental series in $\boldsymbol{A}-\boldsymbol{F}$, myelin profiles tended to be smaller, thinner, less elaborate, and less well compacted in KO $(\boldsymbol{D}-\boldsymbol{F})$ than in WT $(\boldsymbol{A}-\boldsymbol{C})$ mice. These signs of delayed or impaired myelination are evident before eye-opening as shown at P12 in $\mathbf{G}-J$. In contrast to a mixture of profiles representing various stages of myelination in P12 WT mice (G), several examples of abnormal membrane generation and impaired myelination, sometimes associated with axonal degeneration, were apparent in P12 K0 mice $(\boldsymbol{H}-\boldsymbol{J})$. Scale bar: (in $\boldsymbol{F}, \boldsymbol{J}) \boldsymbol{A}-\boldsymbol{J}, 1.0 \mu \mathrm{m}$.

feine were all significantly reduced in the golli KO OLs (Fig. 9A). Importantly, these differences in the $\mathrm{Ca}^{2+}$ response between WT and KO OLs were lost when the cells were in a medium with zero $\mathrm{Ca}^{2+}$ (Fig. 9B). Taken as a whole, these data suggest that OLs from the golli-deficient mice are less responsive to stimulation. These blunted $\mathrm{Ca}^{2+}$ responses may be responsible for the altered patterns of OL process extension and myelination.

\section{Discussion}

It has been known for some time that the mbp gene encodes two families of proteins that include the golli proteins and the classic MBPs, but relatively little is known about the biological roles of the golli proteins or even whether they have any relevance to OL function (Campagnoni and Skoff, 2001). We generated a mouse in which the golli products were selectively ablated to determine whether these proteins play an important biological role in either neurons or OLs, the major cell types in the brain in which the golli proteins are expressed.

In this study, we show by several criteria that OLs and their function are impaired by the selective ablation of golli proteins. The KO animals suffer from delayed and reduced myelination in selective regions of the brain, and this hypomyelination appears to be long-lasting in some areas, such as the visual cortex. This manifests itself as a physiological abnormality in parallel visual evoked potential studies. Ultrastructural analyses demonstrate both hypomyelination as well as abnormal myelin formation in certain areas of the forebrain. That at least part of this hypomyelination is caused by intrinsic problems with the oligodendrocyte is indicated by the impaired formation of myelin sheets by primary cultures of cortical OLs and the presence of abnormal $\mathrm{Ca}^{2+}$ transients in purified cortical OLs studied in vitro.
P12 Visual Cortex

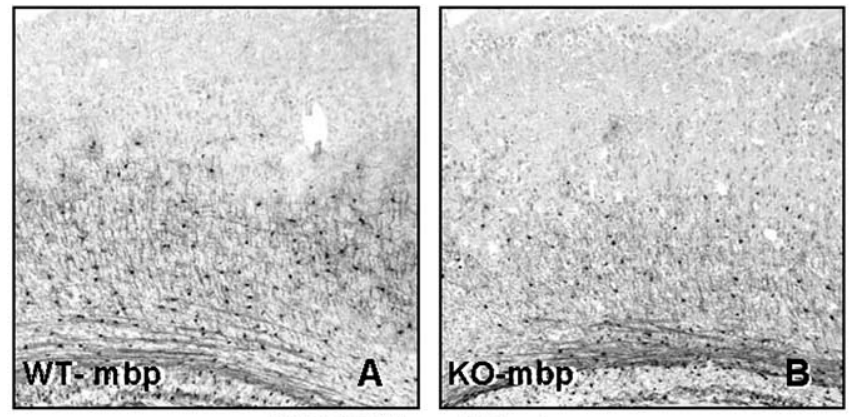

P89-90 Visual Cortex
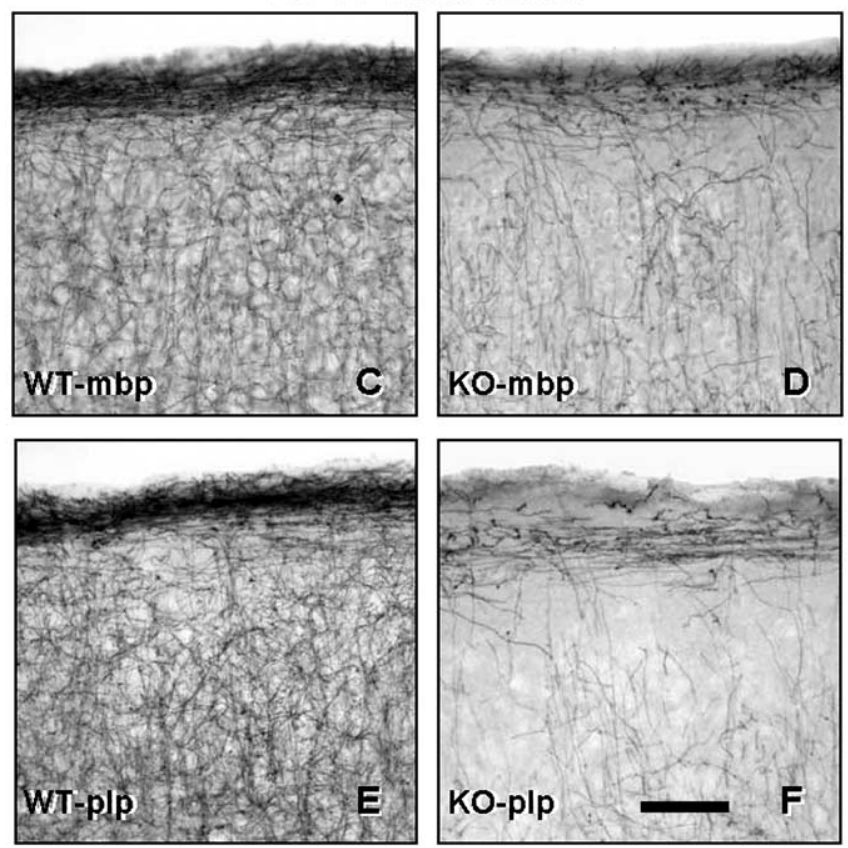

Figure 6. $A-F$, Immunohistochemistry for MBP and PLP detected fewer labeled cells and fibers in the KO visual cortex $(\boldsymbol{B}, \boldsymbol{D}, \boldsymbol{F})$ than in the WT $(\boldsymbol{A}, \boldsymbol{C}, \boldsymbol{E})$, confirming the reduction in myelinated profiles in this region shown in Figure 5 . At both early $(\boldsymbol{A}, \boldsymbol{B})$ and older $(\boldsymbol{C}-\boldsymbol{F})$ ages, immunohistochemical labeling was sparse in the visual cortex. Scale bar: (in $\boldsymbol{F}) \boldsymbol{A}, \boldsymbol{B}, 370 \mu \mathrm{m}$; $(-F, 75 \mu \mathrm{m}$.

Previous work in our laboratory has established that golli is involved in signaling mechanisms within the T-cell (Feng et al., 2004). In this system, overexpression of the golli isoform BG21 inhibits the ability of the cell to produce interleukin- 2 in response to T-cell receptor activation. Golli is not a structural component of myelin. Thus, it seems likely that the abnormal myelin phenotype exhibited in the golli KO mouse is also related to some sort of signaling function for golli in the oligodendrocyte.

The modulation of local internal $\mathrm{Ca}^{2+}$ levels is important in many of the second messenger systems associated with the receptors that determine the response of a cell to signals from its surroundings. As with neurons and astrocytes, activation of the $\mathrm{IP}_{3}$ receptor can cause $\mathrm{Ca}^{2+}$ waves from cell to cell in cultured oligodendrocytes, suggesting that $\mathrm{Ca}^{2+}$ may be important in cell-cell communication (Simpson et al., 1997). Oligodendrocyte process extension in response to PMA (Yoo et al., 1999) and oligodendrocyte migration in response to FGF-2 (Simpson and Armstrong, 1999) are dependent on $\mathrm{Ca}^{2+}$ influx. In studies by $\mathrm{Paz}$ Soldan et al. (2003), the ability of a monoclonal antibody to promote remyelination in a Theiler's murine encephalomyelitis virus-infected mouse demyelinating model correlated with the 


\section{P50 Visual Cortex - MBP}

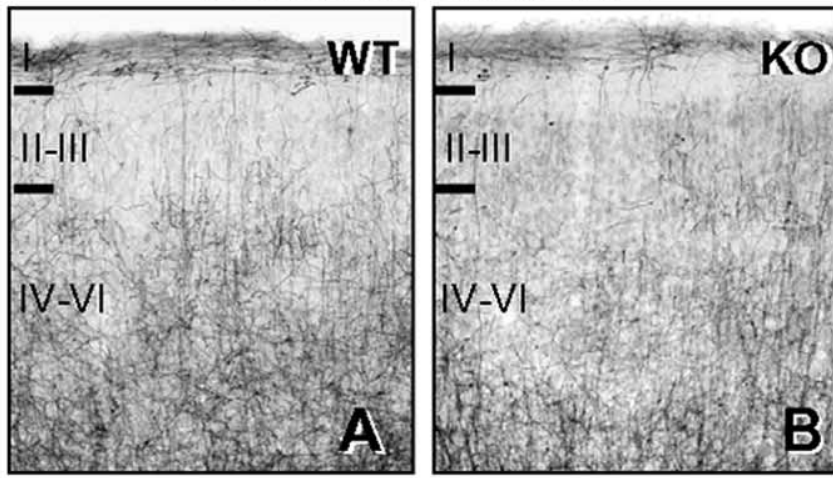

P50 Visual Cortex - PLP
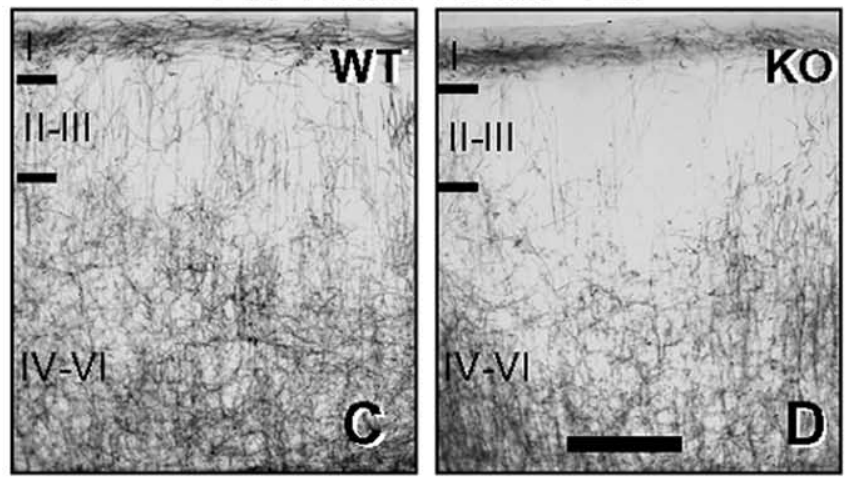

E

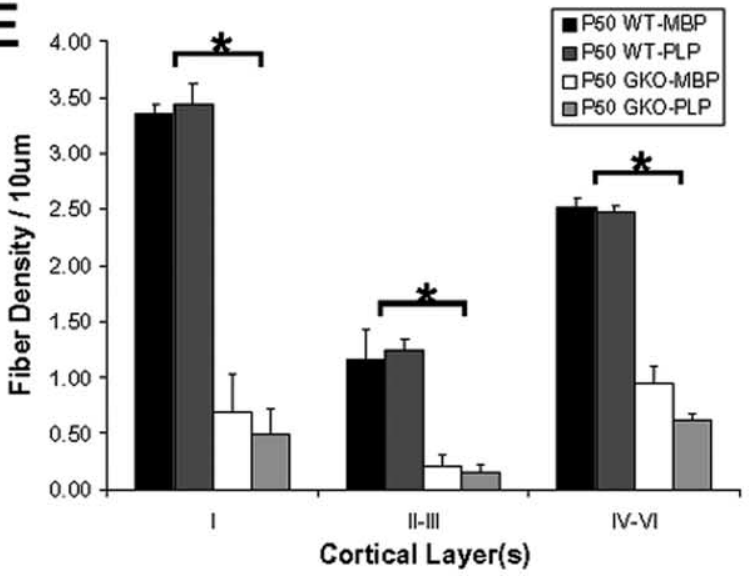

Figure 7. At P50, immunohistochemical labeling for MBP and PLP detected significantly fewer labeled fibers $\left({ }^{*} p>0.05 ; \boldsymbol{E}\right)$ throughout the visual cortex of the $\mathrm{K} 0$ mouse $(\boldsymbol{B}, \boldsymbol{D})$ than in the WT $(\boldsymbol{A}, \boldsymbol{C})$. The greatest reduction of label was in the plexiform outer zones of layer 1 near the pial surface and the underlying cellular zones of the $\mathrm{KO}$ mice ( $82 \%$ in layer I and $83 \%$ in layers $\|-I I \mid, E)$. This reduction in labeled cells and fibers may be caused by impaired $0 \mathrm{~L}$ migration into these regions during development, which results in fewer myelinating $0 \mathrm{Ls}$ and/or dysmyelination. Whatever the mechanism, hypomyelination in this region persisted into adulthood. Significant differences were not detected between the number of PLP and MBP positive fibers within any given layer for each genotype. Error bars show SEM. Scale bar: (in $\boldsymbol{D}) \boldsymbol{A}-\boldsymbol{D}, 150 \mu \mathrm{m}$.

ability of these antibodies to induce a $\mathrm{Ca}^{2+}$ influx in isolated oligodendrocytes, suggesting that $\mathrm{Ca}^{2+}$ surges may also be involved in the signal for myelination. The blunted $\mathrm{Ca}^{2+}$ responses we observed in our $\mathrm{Ca}^{2+}$ imaging reported here suggest that the golli depletion could also have an effect on the differentiation or migration signaling pathways in oligodendrocytes.

Several examples of both spontaneously occurring and targeted ablation of myelin proteins have been reported. Ablation of the classic MBPs causes a severe neurological phenotype in the

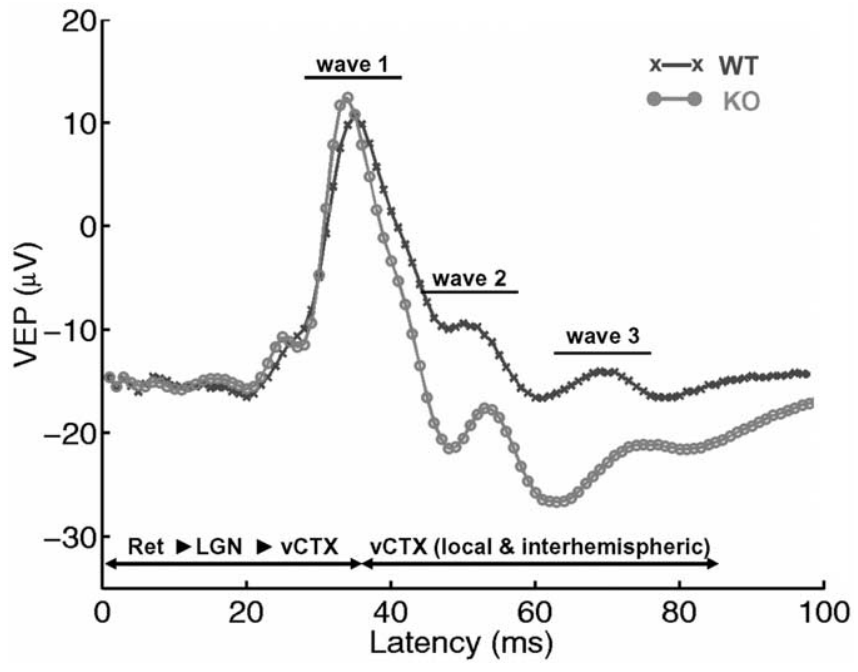

Figure 8. VEPs on $28 \mathrm{~d}$ golli $\mathrm{KO}$ and WT mice. Individual results of three $\mathrm{KO}$ and four WT were averaged within each genotype. Cortical (but not subcortical) sources of VEP waves 2 and 3 are delayed in the golli $\mathrm{KO}$ mice. These results suggest that waves derived from cortical connections [e.g., local (wave 2) and commissural-associational (wave 3) axonal collaterals] are affected in golli KO mice and provide a physiological correlate of the hypomyelination observed in the histological studies of this region. Ret, Retina; LGN, lateral geniculate nucleus; vCTX, visual cortex.
A

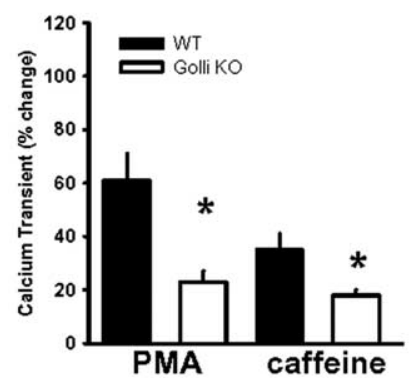

B

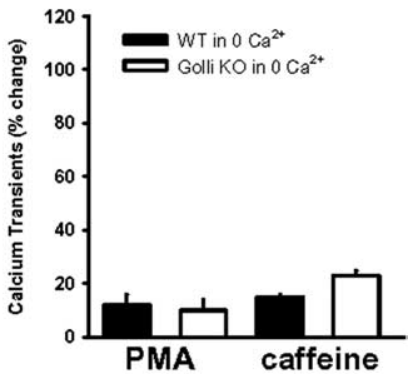

Figure 9. Optical imaging techniques were used to measure calcium levels in OLs from WT and golli-deficient mice. $A$, Histograms showing peak calcium transients from treatment with PMA and caffeine in OLs isolated from WT (black bars) and golli KO (white bars) mice. Significant differences $(p<0.01)$ are indicated by the asterisks. $\boldsymbol{B}$, Histograms showing peak calcium transients from the same treatments as is $\boldsymbol{A}$ in the absence of extracellular calcium. All groups were significantly reduced in the absence of calcium. Error bars are shown as SEM.

case of the shiverer (shi) mouse, which arose as a spontaneously occurring mutant (Wolf and Billings-Gagliardi, 1984). In the shi mouse, there is substantial hypomyelination associated with tremors, and even seizures, resulting in the premature death of some homozygous animals. The targeted ablation of the PLP and myelin-associated glycoprotein (MAG) genes has resulted in $\mathrm{KO}$ mice with no obvious neurological or dysmyelinating phenotype. However, neuronal abnormalities develop in both of these mice at later postnatal ages, and in the MAG KO, myelin degeneration is observed (Fruttiger et al., 1995; Klugmann et al., 1997).

The golli $\mathrm{KO}$ mouse described here has a phenotype unlike any of these other myelin protein KO animals. Like the PLP and MAG KOs, there is no overt dysmyelinating neurological phenotype. Unlike these KOs, however, hypomyelination begins early in postnatal development in the golli KO in selected regions of the brain and persists into adulthood in some regions of the forebrain. 
An unusual phenotypic characteristic of the golli KO animals is the rather selective nature of the localization of the hypomyelination. It would appear to occur in well defined white matter tracts, such as the optic nerve, as well as within the gray matter of the cerebral cortex.

The lack of myelination in the visual cortex of the golli KO mouse could be because of an effect of the ablation on axonal elaboration or survival in this region. Without the axonal substrate to myelinate, then the hypomyelination could be a secondary effect. We do not think this is likely, because we have no histological or immunocytochemical evidence of such a massive loss of fibers in this region, although we found signs of increased neuronal cell death. Also, the in vitro studies on cultured OLs are consistent with an intrinsic myelination defect in the cortical OLs.

A more likely interpretation of these findings is that the selective hypomyelination is caused by OL heterogeneity within the brain. There may be some subsets of OLs or their precursors in which golli plays a more necessary role than in others. Although myelination occurs generally from the spinomedullary junction to the forebrain, within a single region, myelination is not synchronous. The development of individual CNS regions occurs along different schedules, with wide variations in the timing of gliogenesis (Noble et al., 2003), and the cerebral cortex exhibits the widest range of timing for myelination. It begins later than many other CNS regions (Macklin and Weill, 1985; Kinney et al., 1988; Foran and Peterson, 1992) and extends over long time periods (Noble et al., 2003).

In addition to differences in the timing, there is evidence of differences in the origin of the OLs. There is abundant evidence in the rodent that OLs populating the cortex arise during early postnatal life from OPCs generated in the cortical subventricular zone (SVZ) (Curtis et al., 1988; LeVine and Goldman, 1988; Hardy and Reynolds, 1991; Levison et al., 1993; Zerlin et al., 1995). Recently, Ivanova et al. (2003) have presented evidence that OPCs generated embryonically migrate to the cortex from the medial ganglionic eminence, rather than the SVZ, and are involved in myelinating cortical gray matter. They have proposed that cortical OLs are generated in two developmental waves and that cortical gray and white matter might be myelinated by different subpopulations of OLs.

Other evidence supporting the notion of OL heterogeneity include: differences in regional OL cycling times when exposed to PDGF in vitro and differences among OPCs in signaling molecules and transcription factors (for review, see Noble et al., 2003), regional and cellular heterogeneity in morphology (Del RioHortega, 1928; Weruaga-Prieto et al., 1996), and differences in complements of trk receptors (Du et al., 2003) and other receptors (Kettenmann et al., 1984; Takeda et al., 1995). It is possible that some subsets of OLs are more sensitive to golli ablation and others are more refractory because of compensation mechanisms. Our $\mathrm{Ca}^{2+}$ imaging studies in isolated golli KO OLs in this study support the notion of OL heterogeneity and are consistent with a role for golli in differentiation, migration, and/or myelination, given the importance of $\mathrm{Ca}^{2+}$ changes in this process.

In summary, we have produced a golli $\mathrm{KO}$ mouse in which selective ablation of the golli products of the $m b p$ gene has been achieved. During early postnatal development, classic MBP expression underwent a transient delay, and in vitro experiments with cultured OLs indicated a delay in KO OL process extension and membrane formation. Although gross myelination appeared normal, more careful electron microscopic and immunohistochemical studies indicated that myelination in vivo was delayed and that the myelin was morphologically abnormal, particularly in specific regions such as the visual cortex. These data support an important role for golli proteins in OL differentiation/migration and/or myelin elaboration by the oligodendrocyte.

\section{References}

Amur-Umarjee S, Phan T, Campagnoni AT (1993) Myelin basic protein mRNA translocation in oligodendrocytes is inhibited by astrocytes in vitro. J Neurosci Res 36:99-110.

Amur-Umarjee SG, Dasu R, Campagnoni AT (1990) Temporal expression of myelin-specific components in neonatal mouse brain cultures: evidence that 2,3-cyclic nucleotide 3-phosphodiesterase appears prior to galactocerebroside. Dev Neurosci 12:251-262.

Campagnoni AT, Skoff RP (2001) The pathology of myelin mutants reveal novel biological functions of the MBP and PLP genes. Brain Pathol 11:74-91.

Campagnoni AT, Pribyl TM, Campagnoni CW, Kampf K, Amur-Umarjee S, Landry CF, Handley VW, Newman SL, Garbay B, Kitamura K (1993) Structure and developmental regulation of Golli-mbp, a $105 \mathrm{~Kb}$ gene that encompasses the myelin basic protein gene and is expressed in cells in the oligodendrocyte lineage in the brain. J Biol Chem 268:4930-4938.

Colwell CS (2000) Circadian modulation of calcium levels in cells in the suprachiasmatic nucleus. Eur J Neurosci 12:571-576.

Curtis R, Cohen J, Fok-Seang J, Hanley MR, Gregson NA, Reynolds R, Wilkin GP (1988) Development of microglial cells in rat cerebellum. I. Use of antibodies to follow early in vivo development and migration of oligodendrocytes. J Neurocytol 17:43-54.

Del Rio-Hortega P (1928) Tercera aportacion al cenocimiento morfologico e interpretacion funcional de la oligodendroglia. Mem Real Soc Esp Hist Nat 14:40-122.

Du Y, Fischer TZ, Lee LN, Lercher LD, Dreyfus CF (2003) Regionally specific effects of BDNF on oligodendrocytes. Dev Neurosci 25:116-126.

Feng JM, Fernandes AO, Campagnoni CW, Hu YH, Campagnoni AT (2004) The golli-myelin basic protein negatively regulates signal transduction in T lymphocytes. J Neuroimmunol 152:57-66.

Foran DR, Peterson AC (1992) Myelin acquisition in the central nervous system of the mouse revealed by an MBP-Lac Z transgene. J Neurosci 12:4890-4897.

Fruttiger M, Montag D, Schachner M, Martini R (1995) Crucial role for the myelin-associated glycoprotein in the maintenance of axon-myelin integrity. Eur J Neurosci 7:511-515.

Grynkiewicz G, Poenie M, Tsien RY (1985) A new generation of Ca2+ indicators with greatly improved fluorescence properties. J Biol Chem 260:3440-3450.

Hardy R, Reynolds R (1991) Proliferation and differentiation potential of rat forebrain oligodendroglial progenitors both in vitro and in vivo. Development 111:1061-1080.

Itoh T, Beesley J, Itoh A, Cohen AS, Kavanaugh B, Coulter DA, Grinspan JB, Pleasure D (2002) AMPA glutamate receptor-mediated calcium signaling is transiently enhanced during development of oligodendrocytes. J Neurochem 81:390-402.

Ivanova A, Nakahira E, Kagawa T, Oba A, Wada T, Takebayashi H, Spassky N, Levine J, Zalc B, Ikenaka K (2003) Evidence for a second wave of oligodendrogenesis in the postnatal cerebral cortex of the mouse. J Neurosci Res 73:581-592.

Jacobs EC, Bongarzone ER, Campagnoni CW, Kampf K, Campagnoni AT (2003) Soma-restricted products of the myelin proteolipid gene are expressed primarily in neurons in the developing mouse nervous system. Dev Neurosci 25:96-104.

Kaur J, Libich DS, Campagnoni CW, Wood DD, Moscarello MA, Campagnoni AT, Harauz G (2003) Expression and properties of the recombinant murine Golli-myelin basic protein isoform J37. J Neurosci Res 71:777-784.

Kettenmann H, Gilbert P, Schachner M (1984) Depolarization of cultured oligodendrocytes by glutamate and GABA. Neurosci Lett 47:271-276.

Kinney HC, Brody BA, Kloman AS, Gilles FH (1988) Sequence of central nervous system myelination in human infancy. II. Patterns of myelination in autopsied infants. J Neuropathol Exp Neurol 47:217-234.

Klugmann M, Schwab MH, Puhlhofer A, Schneider A, Zimmermann F, Griffiths IR, Nave KA (1997) Assembly of CNS myelin in the absence of proteolipid protein. Neuron 18:59-70.

Landry CF, Pribyl TM, Ellison JA, Givogri MI, Kampf K, Campagnoni CW, 
Campagnoni AT (1998) Embryonic expression of the myelin basic protein gene: identification of a promoter region that targets transgene expression to pioneer neurons. J Neurosci 18:7315-7327.

LeVine SM, Goldman JE (1988) Spatial and temporal patterns of oligodendrocyte differentiation in rat cerebrum and cerebellum. J Comp Neurol 277:441-455.

Levison SW, Chuang C, Abramson BJ, Goldman JE (1993) The migrational patterns and developmental fates of glial precursors in the rat subventricular zone are temporally regulated. Development 119:611-622.

Macklin WB, Weill CL (1985) Appearance of myelin proteins during development in the chick central nervous system. Dev Neurosci 7:170-178.

Martin M, Hiltner TD, Readhead C, Fraser SE, Jacobs RE (2003) Myelin deficiencies visualized in vivo. J Neurochem [Suppl] 85:100.

Michel S, Itri J, Colwell CS (2002) Excitatory mechanisms in the suprachiasmatic nucleus: the role of AMPA/KA glutamate receptors. J Neurophysiol 88:817-828.

Noble M, Arhin A, Gass D, Mayer-Proschel M (2003) The cortical ancestry of oligodendrocytes: common principles and novel features. Dev Neurosci 25:217-233.

Olmstead C, Pribyl T, Kampf K, Jacobs E, Campagnoni C, Handley V, Skinner E, Messing A, Lazareff J, Campagnoni A (2000) Targeted ablation of the Golli products of the myelin basic protein gene: learning deficits. Soc Neurosci Abstr 26.30.17.

Paz Soldan MM, Warrington A, Bieber AJ, Ciric B, Van Keulen VK, Pease LR, Rodriguez M (2003) Remyelination-promoting antibodies activate distinct $\mathrm{Ca}^{+2}$ influx pathways in astrocytes and oligodendrocytes: relationship to the mechanism of myelin repair. Mol Cell Neurosci 22:14-24.

Pribyl TM, Campagnoni CW, Kampf K, Kashima T, Handley VW, McMahon J, Campagnoni AT (1993) The human myelin basic protein gene is included within a 179-kilobase transcription unit: expression in the immune and central nervous systems. Proc Natl Acad Sci USA 90:10695-10699.

Reyes SD, Campagnoni AT (2002) Two separate domains in the golli myelin basic proteins are responsible for nuclear targeting and process extension in transfected cells. J Neurosci Res 69:587-596.

Simpson PB, Armstrong RC (1999) Intracellular signals and cytoskeletal elements involved in oligodendrocyte progenitor migration. Glia 26:22-35.

Simpson PB, Mehrotra S, Lange GD, Russell JT (1997) High density distribution of endoplasmic reticulum proteins and mitochondria at specialized $\mathrm{Ca}^{+2}$ release sites in oligodendrocyte processes. J Biol Chem 36:22654-22661.

Soliven B (2001) Calcium signaling in cells of oligodendroglial lineage. Microsc Res Tech 52:672-679.

Strain GM, Tedford BL (1993) Flash and pattern-reversal visual-evoked potentials in C57BL/6J and B6CBAF1/J mice. Brain Res Bull 32:57-63.

Suzumura A, Bhat S, Eccleston PA, Lisak RP, Silberberg DH (1984) The isolation and long-term culture of oligodendrocytes from newborn mouse brain. Brain Res 324:379-383.

Takeda M, Nelson DJ, Soliven B (1995) Calcium signaling in cultured rat oligodendrocytes. Glia 14:225-236.

Voskuhl RR, Pribyl TM, Kampf K, Handley V, Liu H-b, Feng JM, Campagnoni CW, Soldan SS, Messing A, Campagnoni AT (2003) Experimental autoimmune encephalomyelitis relapses are reduced in heterozygous golli MBP knockout mice. J Neuroimmunol 139:44-50.

Weruaga-Prieto E, Eggli P, Celio MR (1996) Topographic variations in rat brain oligodendrocyte morphology elucidated by injection by injection of Lucifer Yellow in fixed tissue slices. J Neurocytol 25:19-31.

Wolf MK, Billings-Gagliardi S (1984) CNS hypomyelinated mutant mice (jimpy, shiverer, quaking): in vitro evidence for primary oligodendrocyte defects. Adv Exp Med Biol 181:115-133.

Yoo ASJ, Krieger C, Kim S (1999) Process extension and intracellular $\mathrm{Ca}^{2+}$ in cultured murine oligodendrocytes. Brain Res 827:19-27.

Zerlin M, Levison SW, Goldman JE (1995) Early patterns of migration, morphogenesis, and intermediate filament expression of subventricular zone cells in the postnatal rat forebrain. J Neurosci 15:7238-7249. 